\title{
On Generalization to Develop Model of Details of the Leaf Margin using the B-Spline Offset Research on the Leaf Shape Modeling
}

\author{
Norazman Arbin, Siti Noor Asyikin Mohd Razali, Mustafa Mamat
}

\begin{abstract}
The aim of this research is to develop a new model of details for the leaf serration before wrapping it onto the overall leaf margin. For this purpose, we used the offset of the original leaf shape outline. The model of the leaf consists of several leaf parts are represented with B-spline curves which also represent the offset. We propose a new algorithm to represent the pattern of the details. The details are applied as an offset to the underlying curve. An algorithm how the pattern combines to the margin was also explained. The results of the drawings are divided into three categories: satisfactory, acceptable, and unsatisfactory. Expert botanist was referred to assess the drawing result to ensure the result is parallel with a botanical point of view. The findings show that the geometry of the details was satisfactory, except for some minor distortion. As the implication, this research allows novice botanists and amateurs to readily see a picture which they might find it hard to visualize before.
\end{abstract}

Index Terms - B-splines curve, offset, serration, underlying curve.

\section{INTRODUCTION}

The work for curve editing using multiresolution have been studied and explored by many researchers. In [1] has developed multiresolution representations based on wavelet. Their work mainly focused on parametric curves. Meanwhile, the work by [2], [3] has explored the multiresolution editing or deformation techniques by using $B$-splines especially for parametric curves. In multiresolution analysis [4], it can be extended and generalized not only to tensor-product surfaces, but even to surfaces of arbitrary topological type. In [5] has concentrated their work on the constraint of constant enclosed area, while in [6] started the multiresolution editing of curve with three dimensional representation.

In order to produce details of the leaf margin, we initially have tried the multiresolution approach by [2]. However, the main constraint was that their approach was limited by the number of control points. It does not mean that their approach was totally not suitable, but we only manage to produce only certain amount of details of the leaf margin. As we desire to have a more flexibility on the amount of the details, we instead use the offset approach. For this purpose, we use two $B$-spline curves where one of them is the offset of the other. Many articles such as [7]-[10] have discussed the offset of the B-spline curve. Mostly their approach explain the offset curve can be defined by new control points, where each control point is the offset of a control point of the original curve. However, the main concern was that it is not easy to generate the details onto the $B$-spline curve as it requires complex mathematical understanding. We instead use an offset point from the equally spaced points on the $B$-spline curve.

\section{TO DEVELOP MODEL OF THE DETAILS}

The development of the details is explained first before wrapping it onto the composite curve. Generally, the idea is to have two sets of sampling points which are equally spaced on the B-spline curve. Taken into account the work by [11], consider $D(u)$ is the basic leaf shape of the composite curve where $u$ the equally spaced sampling point is. This results in an equation in a form of $D(u)+d(u) N(u)$, where $d(u)$ is the height of a tooth, and $N(u)$ normal to the shape which makes the tooth locally oriented. The $d(u)$ also can be said to be the pattern in a straight line which represents serrate geometry. For each tooth, the equally spaced points for serrate is shown in Fig. 1. The principal used to produce serrate is as $d(u)=\left\{\begin{array}{l}d=-u \quad \text { if } u_{1,3, \ldots,-3} \leq u_{2,4, \ldots, p-2} \\ d=\frac{u_{p}-u}{u_{p}+u_{1}} \text { if } u_{1,3, \ldots, p-3} \leq u_{4,6, \ldots, p}\end{array}\right.$ and this is illustrated in Fig. 2.

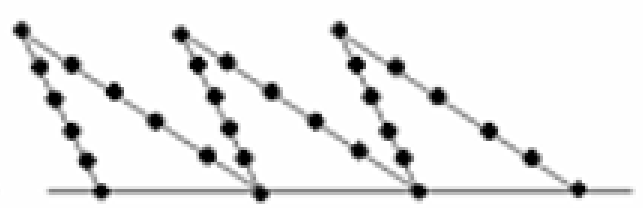

Fig. 1: Serrate equally spaced point

Revised Manuscript Received on July 10, 2019.

Norazman Arbin, Faculty of Science and Mathematics, Universiti Pendidikan Sultan Idris, Perak, Malaysia.

Siti Noor Asyikin Mohd Razali, Department of Mathematics and Statistic, Faculty of Applied Science and Technology, Universiti Tun Hussein Onn Malaysia, Johor, Malaysia.

Mustafa Mamat, Faculty of Informatics and Computing, Universiti Sultan Zainal Abidin, Terengganu, Malaysia. 


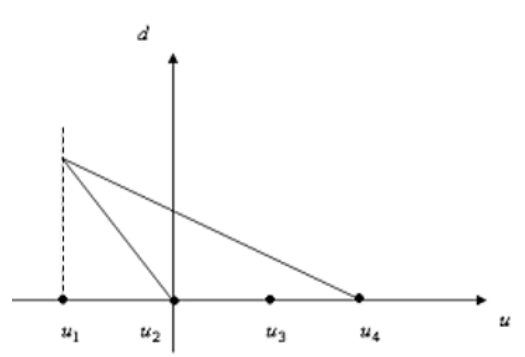

Fig. 2: Serrate tooth

To add the teeth to the leaf margin, the following algorithm applies:

1. To produce the first sample points, the first curve of the whole leaf is sampled with 100 equally points, denoted as $\mathrm{p}_{i} ; \quad i=1, \ldots, 100$

2. To produce the second, the teeth are generated by using the offset approach, producing points $\mathrm{t}_{j} ; j=1,2, \ldots, k$; where $k$ is an integer which is determined by the type of the teeth

3. The sample curve $\mathrm{A}_{i}$ is given by

$\mathrm{A}_{i}=\left[\begin{array}{l}\mathrm{p}_{1}, \mathrm{p}_{2}, \ldots, \max \left(\mathrm{p}_{i}\right)<\mathrm{t}_{j}, \mathrm{t}_{1}, \mathrm{t}_{2}, \ldots, \mathrm{t}_{k}, \min \left(\mathrm{p}_{i}\right)<\mathrm{t}_{k}, \ldots, \\ \mathrm{p}_{100}\end{array}\right]$

\section{RESULTS AND DISCUSSION}

From botanical books [12]-[16], samples of 50 leaf descriptions which have serrate are carefully chosen. The Leaf Synthesis System [17] was used to test the idea. Expert botanists were referred to assess the drawing results. The quality of the leaf drawing is divided into three categories which are satisfactory, acceptable, and unsatisfactory [11], focuses on the overall shape which consists of three dimensions which are: (a) overall shape of leaf which consist of the aspect ratio, side, tip and base geometry; (b) teeth size; and (c) teeth location. Table 1 shows the analysis of mean for the dimension of all cases. The mean values

Table 1: Mean score for each category

\begin{tabular}{|c|c|}
\hline Dimension & Mean Score \\
\hline Overall shape of leaf & 2.75 \\
\hline Overall size of teeth & 2.82 \\
\hline Overall teeth location & 2.71 \\
\hline
\end{tabular}

Following Fig. 3 is some of the results using [17].

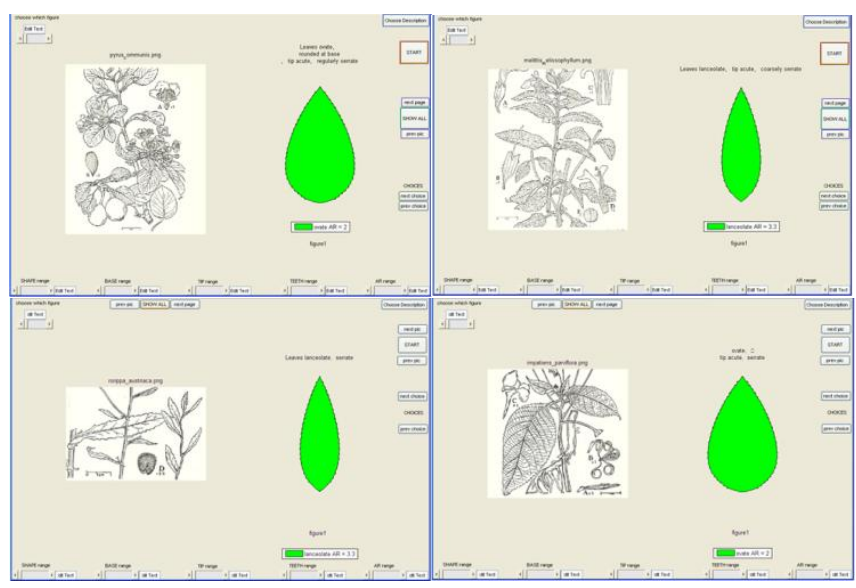
show that they falls under satisfactory category.

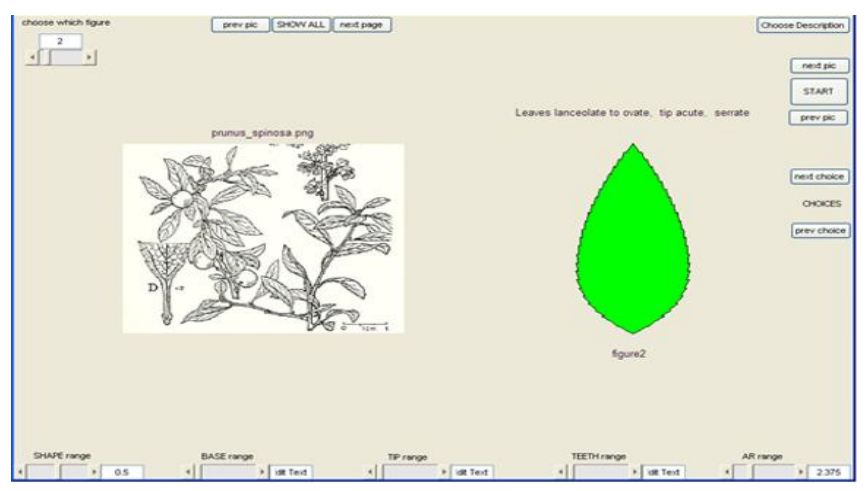

Fig. 3: Leaf synthesis system

\section{CONCLUSION}

The main goal of this research to develop pattern for serrate and add the details to the leaf margin has been achieved with the overall results of $94 \%$ (mean score of 2.82) satisfactory cases. It shows that the approach used is practical and successful. Although the result is not perfect, but it is not too bad. There are some distortions to the teeth when bending the straight line. However, the distortion is not important in the overall picture. The overall teeth size and shape are still correct and the program still manage to produce reasonable drawing and identify the species.

\section{ACKNOWLEDGMENT}

This research is funded by the Malaysian Ministry of Education via Fundamental Research Grant Scheme (FRGS/1/2017/STG06/Unisza/01/1).

\section{REFERENCES}

1. C. Chui, and E. Quak, "Wavelet on a bounded interval," in Numerical Methods of Approximation Theory, D. Braess and L. L. Schumaker, Eds. Basel: Birkhauser Verlag, 1992, pp. 124.

2. A. Finkelstein, and D.H. Salesin, "Multiresolution curves," Computer Graphics, 28, 1994, pp. 261-268.

3. F. F. Samavati, and R. H. Bartels, "Multiresolution curve and surface representation: Reversing subdivision rules by leastsquares data fitting," Computer Graphics Forum, 18(2), 2001, pp. 97-118.

4. M. Lounsbery, T. DeRose, and J. Warren, "Multiresolution analysis for surface of arbitrary topological type," ACM Transaction on Graphics, 16, 1997, pp. 34-73.

5. S. Hahmann, G. Bonneau, and B. Sauvage, "Area preserving deformation of multiresolution curves," Computer Aided Geometric Design, 22(4), 2015, pp. 349-367.

6. B. Sauvage, S. Hahmann, and G.P. Bonneau, "Length constraint multiresolution for surface wrinkling," IEEE International Conference on Shape Modeling and Application, 21, 2006, pp. 251-256.

7. J. L. Gu, Y. H. Jung, K. W. Lee, and D.W. Lee, "Approximation of planar offset curves using quadratic trigonometric splines with shape parameter," International Journal of Precision Engineering and Manufacturing, 14(11), 2013, pp. 1881-1890. 
8. H. Y. Zhao, and H. M. Zhou, "Offset approximation along the offset direction for planar curve," IEEE Fourth International Symposium on Computational Intelligence and Design, 2011, pp. 144-148.

9. H. Y. Zhao, and G. J. Wang, "Offset approximation based on reparameterizing the path of a moving point along the base circle," Applied Mathematics, 24(4), 2009, pp. 431-442.

10. L. L. Ge, and Y. J. Zhang, "New approach to computation of offset curve for point-based geometries," 3rd IEEE Conference on Industrial Electronics and Applications, 2008, pp. 367-371.

11. N. Arbin, S. R. M. Sabri, M. S. Idris, and S. N. A. M. Razali, "Development of algorithms and serration model to add details to the leaf margin of the leaf shape modeling by using offset approach," Far East Journal of Mathematical Sciences, 100(12), 2016, pp. 2081-2088.

12. C. Stace, New Flora of The British Isles. England: Cambridge University Press, 2010.

13. R. W. Butcher, A New Illustrated British Flora Part I. England: Leonard Hill, 1961.

14. W. K. Martin, The Concise British Flora in Colour. London: Ebury Press and Micheal Joseph, 1976.

15. R. D. Meikle, Willows and Poplars of Great Britain and Ireland. Durham: Botanical Society of the British Isles, 2006.

16. T. C. G. Rich, and A. C. Jermy, Plant Crib. Durham: Botanical Society of the British Isles, 2012.

17. N. Arbin, Z. Mohamed, S. A. Ghani, and A. R. M. Piah, "Development of leaf shape modeling using b-spline generative shape method and leaf shape synthesis," Far East Journal of Mathematical Sciences, 98(8), 2015, pp. 10471054. 